\title{
Impact of Ramadan focused education program on hypoglycemic risk and metabolic control for patients with type 2 diabetes
}

This article was published in the following Dove Press journal:

Patient Preference and Adherence

6 September 2016

Number of times this article has been viewed

\author{
Ayla M Tourkmani' \\ Mohamed Azmi Hassali² \\ Turki J Alharbi' \\ Hesham I Alkhashan' \\ Aljoharah H Alobikan' \\ Ahmed H Bakhiet' \\ Hala B Alqahtani' \\ Alian A Alrasheedy ${ }^{3}$ \\ Ahmed D Alawwad' \\ Adel M Mishriky' \\ Hisham Aljadhey ${ }^{4}$ \\ 'Family and Community Medicine \\ Department, Prince Sultan Military \\ Medical City, Riyadh, Saudi Arabia; \\ ${ }^{2}$ Discipline of Social and \\ Administrative Pharmacy, School of \\ Pharmaceutical Sciences, Universiti \\ Sains Malaysia, Penang, Malaysia; \\ ${ }^{3}$ Department of Pharmacy Practice, \\ Unaizah College of Pharmacy, Qassim \\ University, Qassim Saudi Arabia; \\ ${ }^{4}$ Medication Safety Research Chair, \\ College of Pharmacy, King Saud \\ University, Riyadh, Saudi Arabia
}

Correspondence: Ayla M Tourkmani Family and Community Medicine Department, Prince Sultan Military Medical City, PO Box 1749, Riyadh I | 44I, Saudi Arabia

Tel +966 | $5029 \mid 222$ |

Email aylatourkmani@gmail.com
Background: Fasting during the month of Ramadan could lead to acute complications and increased hypoglycemic risk of patients with type 2 diabetes. Therefore, diabetes is one of the diseases that need careful observation and special considerations during Ramadan including patients' education and counseling.

Objectives: To evaluate the impact of Ramadan focused education program on acute complications and biomedical parameters.

Methods: A prospective nonrandomized interventional controlled design was run on three phases: before, during, and after Ramadan on 262 type 2 diabetes patients. The intervention group ( $n=140$ ) received focused individualized diabetic education sessions and antidiabetic medications adjustment before and after Ramadan, while the control group $(n=122)$ received standard diabetic care. A validated hypoglycemia questionnaire was used in both groups to assess the change of the risk. Patients were advised to adjust the dosage and timing of antidiabetic agents according to the recommendations for management of diabetes during Ramadan. Primary outcomes were postintervention change of hypoglycemia score and HbA1c over 6-month follow-up. Data were presented as mean \pm standard deviation. HbAlc was expressed in percentage.

Results: The hypoglycemic scores before, during, and after Ramadan were 14.21 \pm 8.50 , $6.36 \pm 6.17$, and $5.44 \pm 5.55$ in the intervention group, respectively $(P<0.001)$ and $14.01 \pm 5.10$, $13.46 \pm 5.30$, and $9.27 \pm 4.65$ in the control group, respectively $(P<0.001)$. HbA1c levels were $9.79 \pm 1.89,8.26 \pm 1.54$, and $8.52 \pm 1.61$ before, during, and after Ramadan in the intervention group, respectively $(P<0.001)$, and $10.04 \pm 1.47,9.54 \pm 1.38$, and $9.59 \pm 1.79$ in the control group, respectively $(P<0.001)$. Post-Ramadan reductions of HbA1c and hypoglycemic scores were significantly higher in the intervention group $(-13.0 \% \mathrm{vs}-4.5 \%, P=0.004$ for $\mathrm{HbA} 1 \mathrm{c}$ and $-61.7 \%$ vs $-33.8 \%, P<0.001$ for hypoglycemic score). Low-density lipoprotein cholesterol improved in the intervention group from $2.41 \pm 0.91 \mathrm{mmol} / \mathrm{L}$ before Ramadan to $2.28 \pm 0.68 \mathrm{mmol} / \mathrm{L}$ after Ramadan $(P<0.001)$. No statistically significant effects were observed on blood pressure or body weight in the intervention group. Also, no change was observed in the control group.

Conclusion: Ramadan educational program had a positive impact with reduction of hypoglycemic risk, HbA1c, and low-density lipoprotein cholesterol. Therefore, it could be recommended for patients with increased risk of hypoglycemia during Ramadan fasting.

Keywords: complications, diabetes, fasting, Saudi Arabia

\section{Introduction}

All healthy nontraveling Muslims are required to abstain from taking any food or beverages between dawn and sunset (fasting) for one complete lunar month every year 
(ie, the month of Ramadan). ${ }^{1}$ Diabetes is one of the key diseases that need careful observation during Ramadan. ${ }^{2}$ Patients with diabetes may face possible major metabolic complications during fasting, including hypoglycemia, hyperglycemia with or without the risk of impending ketosis, dehydration, and thrombosis. ${ }^{3-5}$ Saudi Arabia has one of the highest diabetes prevalence in the world. ${ }^{6,7}$ Additionally, more than half of the top ten countries with the highest diabetes prevalence worldwide have a majority of Muslim population. ${ }^{7}$ Since fasting is regarded by Islam as a way of practicing patience and good manners rather than creating excessive hardship or safety challenge, patients with very high and high risk of diabetic complications as described by the American Diabetic Association are advised not to fast, whereas patients with low and medium risk are expected to fast. ${ }^{8-10}$

Although religiously exempted, the vast majority of Saudi patients with type 2 diabetes (T2D) insist on fasting during Ramadan.,11 As the daily fasting hours varies by season and geographic locations, the current Ramadan seasons come during summer months with hot weather and long fasting duration, reaching $\sim 15$ hours in most Islamic countries, including Saudi Arabia. ${ }^{12}$ This probably increases the risk of acute diabetic complications. Lack of patient education prior to Ramadan may contribute to suboptimal practices. ${ }^{13}$ Many of the diabetic patients who fast in this month without any medical guidance often end up developing acute complications. $^{14}$

Current guidelines recommend that diabetic patients should have counseling and education about the need to modify medication dose and timing, dietary habits, physical activity, and self-monitoring of blood sugar to reduce the risk of acute diabetic complications. ${ }^{3,9}$

Two studies from Pakistan and the UK have shown the Ramadan education program to be successful in protecting against serious acute diabetic complications. ${ }^{15,16}$ Moreover, the current management guidelines stress on individualized approach of diabetic care during Ramadan., ${ }^{3,9}$ Therefore, as diabetes management in Ramadan needs special considerations, there are several guidelines addressing its management in Ramadan, including International Diabetes Federation, the Diabetes and Ramadan International Alliance practical guidelines, ${ }^{17}$ and others. ${ }^{9,18}$

Despite the high prevalence of diabetes and difficult environmental conditions, ${ }^{6,7,12}$ there is a lack of studies that have examined the impact of such focused education program among Saudi patients with T2D. Therefore, the aim of this study is to examine the impact of Ramadan focused education program (RFEP) on hypoglycemia, glycemic control, and other clinical and metabolic parameters among a group of T2D patients receiving care at a primary care center in Riyadh, Saudi Arabia.

\section{Methods}

\section{Setting}

The study was conducted in Al-Wazarat Healthcare Center, a big family medicine center in Riyadh, Saudi Arabia. The total monthly number of diabetic patients visiting the center is $\sim 13,000$. Diabetic patients are served by family medicine clinics (six morning and five afternoon clinics) run by family physicians, a clinical pharmacy clinic (covers ten sessions per week) run by a clinical pharmacist, and other clinics run by diabetic educator, health educator, dietitian, and social worker. The current data are collected from the clinical pharmacy clinic.

\section{Population}

The study included patients with T2D who were receiving care at the Al-Wazarat Healthcare Center at the time of the study. Exclusion criteria included serious comorbidities such as unstable angina or severe hepatic/renal disease, elderly patients with alertness problems, newly diagnosed T2D ( $<3$ months), recent hospitalization, hypoglycemia during the past month or unawareness of hypoglycemia, and partially or completely nonfasting during the month of Ramadan.

\section{Design}

A nonrandomized interventional controlled design was used between June 2013 and February 2014. The study was done in three phases: first phase (2-3 weeks before Ramadan, enrollment), second phase (the third week of Ramadan), and third phase (4 weeks after Ramadan, HbA1c measured 12 weeks after Ramadan). The study was approved by the research committee in Prince Sultan Military Medical City, Riyadh, Saudi Arabia.

\section{Intervention}

The intervention group received the RFEP before and after Ramadan while the control group received standard diabetic care. The standard care was provided as per the American Diabetes Association standard of medical care and guidelines. ${ }^{19-21}$ The RFEP was carried out by the clinical pharmacist, primary care physician, and dietician through individual and/or group sessions (as appropriate) for $\sim 40-60$ minutes. The educational intervention included audiovisual material and written brochures focused on diabetes self-care, including signs and symptoms of hyper- and hypoglycemia, self-monitoring of blood glucose, physical activity, care of diabetic foot, and management of acute 
complications. Patients were encouraged to frequently monitor for glycemia and immediately end their fast in case of hypoglycemia (blood glucose $<60 \mathrm{mg} / \mathrm{dL}$ ). Patients were also advised to adjust the dosage and timing of oral hypoglycemic agents and insulin according to the 2010 recommendations for management of diabetes during Ramadan. ${ }^{9}$ For example, two-third of biguanide or metformin or insulin dose should be given at sunset meal, while a one-third of the dose should be given before the predawn meal. Additionally, patients received individualized diet advice (by dietician), including diet adjustment, preferred and nonpreferred food items, preferred way for breaking fasting, and best timing of second meal. The post-Ramadan education was focused on readjusting antidiabetic medications to prediabetic levels according to blood glucose level and clinical parameters.

\section{Outcome}

The main study outcome was postintervention change of HbA1c and hypoglycemia. Glycemic control was defined as $\mathrm{HbA} 1 \mathrm{c}<7 \%$. The risk of hypoglycemia was assessed using hypoglycemia score. Other outcomes included postintervention change of body weight, blood pressure, and lipid profile. The outcomes were measured before, during, and after Ramadan.

\section{Sampling and recruitment}

Patients were recruited from daily follow-up in the clinical pharmacy clinic using the convenience sampling technique. Patients who meet the eligibility criteria were informed about the study during their regular care before Ramadan. Patients who were able to provide an informed consent were included in the study. The study controls were recruited consecutively after completing the recruitment of the patients in the intervention.

\section{Sample size calculation}

A number of studies showed that the patients who received Ramadan-focused education had $\sim 60 \%$ reduced risk of hypoglycemic events compared to the control group. ${ }^{15,16}$ Therefore, to be able to detect $60 \%$ risk reduction of hypoglycemic events, we estimated that a total of 266 participants are required, assuming 20\% prevalence of hypoglycemic events in the control group, $80 \%$ power, and $95 \%$ two-sided confidence level. Additionally, to detect an absolute difference (increase or reduction) in $\mathrm{HbA} 1 \mathrm{c}$ by $1 \%$, we will need 198 patients (99 in each group) assuming 9\% HbA1c in the control group, standard deviation of $2.5 \%, 80 \%$ power, and 95\% two-sided confidence level.

\section{Data collection tools}

Data were collected through a structured questionnaire, which included sociodemographic information, duration of diabetes, clinical and metabolic parameters, such as body mass index (BMI), systolic and diastolic blood pressure, lipid profile, $\mathrm{HbA} 1 \mathrm{c}$, current antidiabetic medications and hypoglycemia questionnaire introduced by the Hypoglycemic Health Association of Australia. ${ }^{22}$ Face and content validity of the questionnaire was done by three experts in the field of diabetes management. Since the questionnaire needed to be administered in Arabic, bidirectional translation of the questionnaire, including the hypoglycemia part, was done. Additionally, pilot study was done on 15 participants and the feedback was used to improve the understanding of the questionnaire. Reliability of the hypoglycemia questionnaire was found to be satisfactory (Cronbach's alpha of 0.873).

\section{Statistical methods}

Patients' demographic, clinical, and biomedical information were presented as mean and standard deviation for continuous variables, and frequency and percentages for categorical variables. To examine the significance of the changes in glycemic control and other study outcomes across the three phases of the study, repeated measures analysis of variance was run for continuous variables. For the repeated measures analysis of variance, the $P$-value of Wilks' Lambda is reported and when statistically significant, a post hoc analysis was performed using Bonferroni test to adjust for multiple comparisons. For categorical variables, Mantel-Haenszel chi-square was used. To examine the difference in study outcomes between the intervention and control groups during the study phases, independent $t$-test (or its equivalent Mann-Whitney $U$-test) was used for continuous variables and chi-square for categorical variables. The percentage change of the study outcomes was defined as the amount of post-/preintervention change in relation to the preintervention level. The difference in the percentage change of the study outcomes between the two groups were examined using $t$-test, which was used for continuous variables, and chi-square for categorical variables. To detect group difference in post-Ramadan reduction in $\mathrm{HbA} 1 \mathrm{c}$ and hypoglycemia score after adjusting for several demographic characteristics, a multivariate linear regression analysis was run. All $P$-values were two-tailed. $P$-value $<0.05$ was considered as significant. SPSS software (release 20.0, IBM Corporation, Armonk, NY, USA) was used for all statistical analyses. Sample size calculation was done using OpenEpi software (version 2.2, Copyright (C) 2003, 2007 Andrew G. Dean and Kevin M. Sullivan, Atlanta, GA, USA). 


\section{Results}

A total of 262 patients with T2D were included in the study; 140 patients in the intervention group and 122 patients in the control group. The demographic and clinical characteristics of both groups are described in Table 1. The mean age was similar in both groups $(55.12 \pm 12.76$ years in the intervention group vs $56.06 \pm 11.08$ years in the control). The majority of patients were females in both groups $(60.0 \%$ vs $66.4 \%$, respectively). The intervention group and the control group were similar in terms of BMI $(32.93 \pm 6.70 \mathrm{vs}$ $32.71 \pm 7.14$, respectively) similar blood pressure (68.6\% vs $71.3 \%$, respectively, had similar blood pressure). However, a higher proportion of patients in the intervention group were living outside Riyadh compared with the control group ( $14.3 \%$ vs $6.6 \%$, respectively $P=0.043$ ). Also, a higher proportion of the intervention were unemployed compared with the control group (46.4\% vs $12.3 \%$, respectively $P<0.001)$.

Table I Baseline demographic and clinical characteristics in the intervention and control groups

\begin{tabular}{|c|c|c|c|c|}
\hline \multirow[t]{3}{*}{ Variable } & \multirow{3}{*}{$\begin{array}{l}\text { Intervention }(n=\mid 40) \\
\text { Mean } \pm \text { SD } \\
N(\%)\end{array}$} & \multirow{3}{*}{$\begin{array}{l}\text { Control }(n=122) \\
\text { Mean } \pm \text { SD } \\
N(\%)\end{array}$} & \multirow[t]{3}{*}{ Test value } & \multirow[t]{3}{*}{$P$-value } \\
\hline & & & & \\
\hline & & & & \\
\hline \multicolumn{5}{|l|}{ Age (years) } \\
\hline Mean \pm SD & $55.12 \pm 12.76$ & $56.06 \pm 11.08$ & $t=0.630$ & 0.530 \\
\hline$<50$ & $42(30.0)$ & $30(24.6)$ & $\chi^{2}=4.675$ & 0.097 \\
\hline $50-59$ & $52(37.1)$ & $36(29.5)$ & & \\
\hline$\geq 60$ & $46(32.9)$ & $56(45.9)$ & & \\
\hline \multicolumn{5}{|l|}{ Sex } \\
\hline Male & $56(40.0)$ & $4 \mid(33.6)$ & $\chi^{2}=1.143$ & 0.285 \\
\hline Female & $84(60.0)$ & $81(66.4)$ & & \\
\hline \multicolumn{5}{|l|}{ Residence } \\
\hline Riyadh & $120(85.7)$ & II 4 (93.4) & $\chi^{2}=4.079$ & $0.043 *$ \\
\hline Outside Riyadh & $20(14.3)$ & $8(6.6)$ & & \\
\hline \multicolumn{5}{|l|}{ Job status } \\
\hline Unemployed & $65(46.4)$ & $15(12.3)$ & $\chi^{2}=35.809$ & $<0.00 I^{*}$ \\
\hline Working & $75(53.6)$ & $107(87.7)$ & & \\
\hline Body weight & $84.16 \pm 18.04$ & $81.01 \pm \mid 7.71$ & $t=1.395$ & 0.164 \\
\hline \multicolumn{5}{|l|}{ BMI } \\
\hline Mean $\pm S D$ & $32.93 \pm 6.70$ & $32.7 I \pm 7.14$ & $t=0.250$ & 0.803 \\
\hline Normal $(<25)$ & $15(10.7)$ & II (9.0) & $\chi^{2}=|.97|$ & 0.578 \\
\hline Overweight (25-29) & 32 (22.9) & $37(30.3)$ & & \\
\hline Obese (30-34) & $40(28.6)$ & $31(25.4)$ & & \\
\hline Morbid obese $(\geq 35)$ & $50(35.7)$ & 40 (32.8) & & \\
\hline \multicolumn{5}{|l|}{ BP } \\
\hline Hypertension $(>\mid 30 / 80)$ & $96(68.6)$ & $87(71.3)$ & $\chi^{2}=0.232$ & 0.630 \\
\hline Systolic BP & $130.14 \pm 13.85$ & $130.12 \pm 15.40$ & $t=0.011$ & 0.991 \\
\hline Diastolic BP & $73.34 \pm 8.94$ & $72.98 \pm 8.88$ & $t=0.319$ & 0.750 \\
\hline \multicolumn{5}{|c|}{ Diabetes and its management } \\
\hline Duration (years) & $12.95 \pm 8.39$ & $|2.86 \pm 7.6|$ & $U=0.092$ & 0.927 \\
\hline On oral medications & II 8 (84.3) & I0I (82.8) & $\chi^{2}=0.107$ & 0.744 \\
\hline On insulin & $134(95.7)$ & III (9I.0) & $\chi^{2}=2.404$ & 0.121 \\
\hline Number of oral medications & $0.97 \pm 0.55$ & $0.88 \pm 0.47$ & $U=1.479$ & 0.140 \\
\hline Number of insulin types & $\mathrm{I} .7 \mathrm{I} \pm 0.57$ & $1.14 \pm 0.55$ & $U=8.307$ & $<0.00 I^{*}$ \\
\hline Hypoglycemia score & $|4.2| \pm 8.50$ & $|4.0| \pm 5.10$ & $t=0.234$ & 0.815 \\
\hline Acute complications ${ }^{* *}$ & $0(0.0)$ & $6(4.9)$ & $\chi^{2}=7.047$ & $0.008 *$ \\
\hline $\mathrm{HbAlc}$ & $9.79 \pm 1.89$ & $10.04 \pm 1.47$ & $t=-1.196$ & 0.233 \\
\hline \multicolumn{5}{|l|}{ Lipid profile } \\
\hline LDL cholesterol & $2.4 I \pm 0.9 I$ & $2.53 \pm 0.86$ & $t=-|.04|$ & 0.299 \\
\hline HDL cholesterol & $1.14 \pm 0.30$ & I. $14 \pm 0.30$ & $t=-0.075$ & 0.940 \\
\hline Total cholesterol & $4.35 \pm 1.13$ & $4.42 \pm 1.27$ & $t=-0.475$ & 0.635 \\
\hline Triglycerides & $1.62 \pm 0.79$ & $1.86 \pm 1.48$ & $t=-1.665$ & 0.097 \\
\hline
\end{tabular}

Notes: $\chi^{2}$, chi-square test; $t$, Student $t$-test; $U$, Mann-Whitney $U$-test. **Complications that occurred in the previous Ramadan. *Statistically significant difference at $P<0.05$. Abbreviations: BMI, body mass index; BP, blood pressure; HDL, high-density lipoprotein; LDL, low-density lipoprotein; SD, standard deviation. 
The average duration of diabetes was $\sim 13$ years in both groups (Table 1). The majority of patients in both groups were using insulin (95.7\% vs $91.0 \%$, respectively) and oral antidiabetic medications ( $84.3 \%$ vs $82.8 \%$, respectively). Patients in the intervention group had more mixed types of insulin $(1.71 \pm 0.57$ vs $1.14 \pm 0.55, P<0.001)$ but similar number of oral antidiabetic medications. Patients in both groups had similar HbA1c $(9.79 \pm 1.89$ vs $10.04 \pm 1.47$, respectively) and hypoglycemia score $(14.21 \pm 8.50$ vs $14.01 \pm 5.10)$. However, patients in the intervention group had no acute complications compared with $4.9 \%$ in the control group $(P=0.008)$. Both groups had similar lipid profile, including low-density lipoprotein (LDL), high-density lipoprotein, and total cholesterol and triglycerides.

Table 2 summarizes the impact of RFEP on physical, physiological, and biomedical parameters by comparing the

Table 2 Impact of Ramadan focused education program on clinical characteristics during the study phases in the intervention and control groups

\begin{tabular}{|c|c|c|c|c|}
\hline \multirow[t]{2}{*}{ Variable } & \multirow{2}{*}{$\frac{\text { Pre-Ramadan }}{\text { Mean } \pm \text { SD }}$} & \multirow{2}{*}{$\frac{\text { During Ramadan }}{\text { Mean } \pm \text { SD }}$} & \multirow{2}{*}{$\frac{\text { Post-Ramadan }}{\text { Mean } \pm \text { SD }}$} & \multirow{2}{*}{$\frac{\text { Phase difference }}{\text { P-value }}$} \\
\hline & & & & \\
\hline \multicolumn{5}{|l|}{ Body weight (kg) } \\
\hline Intervention & $84.16 \pm 18.04$ & $85.85 \pm 17.37$ & $85.38 \pm 17.09$ & 0.063 \\
\hline Control & $8 I .0 I \pm I 7.7 \mid$ & $81.30 \pm 17.48$ & $80.21 \pm 17.13$ & 0.434 \\
\hline Group difference & $P=0.164$ & $P=0.038^{*}$ & $P=0.017^{*}$ & \\
\hline \multicolumn{5}{|l|}{ BMI } \\
\hline Intervention & $32.93 \pm 6.70$ & $33.74 \pm 6.46$ & $33.49 \pm 6.52$ & 0.296 \\
\hline Control & $32.71 \pm 7.14$ & $32.45^{\#} \pm 7.00$ & $31.50^{\#} \pm 6.63$ & 0.013 \\
\hline Group difference & $P=0.803$ & $P=0.126$ & $P=0.016^{*}$ & \\
\hline \multicolumn{5}{|l|}{ Systolic BP } \\
\hline Intervention & $130.14 \pm 13.85$ & $130.87 \pm 15.57$ & $|30.52 \pm| 5.7 \mid$ & 0.876 \\
\hline Control & $130.12 \pm 15.40$ & $131.20 \pm 15.24$ & $|30.21 \pm| 4.25$ & 0.714 \\
\hline Group difference & $P=0.991$ & $P=0.865$ & $P=0.869$ & \\
\hline \multicolumn{5}{|l|}{ Diastolic BP } \\
\hline Intervention & $73.34 \pm 8.94$ & $72.29 \pm 10.31$ & $72.39 \pm 9.77$ & 0.558 \\
\hline Control & $72.98 \pm 8.88$ & $73.30 \pm 9.30$ & $72.98 \pm 8.78$ & 0.925 \\
\hline Group difference & $P=0.750$ & $P=0.408$ & $P=0.605$ & \\
\hline \multicolumn{5}{|l|}{ LDL cholesterol } \\
\hline Intervention & $2.4 I^{\#} \pm 0.91$ & $2.12^{\#, \$} \pm 0.68$ & $2.28^{\$ \pm 0.73}$ & $<0.00 I^{*}$ \\
\hline Control & $2.53 \pm 0.86$ & $2.46 \pm 0.89$ & $2.60 \pm 0.98$ & 0.109 \\
\hline Group difference & $P=0.299$ & $P=0.00 I^{*}$ & $P=0.003^{*}$ & \\
\hline \multicolumn{5}{|l|}{ HDL cholesterol } \\
\hline Intervention & $1.14^{\#, \$ \pm 0.30}$ & $1.19^{\#} \pm 0.31$ & $1.23^{\$} \pm 0.38$ & $0.00 I^{*}$ \\
\hline Control & $1.14^{\#, \$ \pm 0.30}$ & $\mathrm{I} .24^{\#, \wedge} \pm 0.33$ & $1.29^{\$ \wedge} \pm 0.34$ & $<0.00 I^{*}$ \\
\hline Group difference & $P=0.940$ & $P=0.21 \mathrm{I}$ & $P=0.214$ & \\
\hline \multicolumn{5}{|l|}{ Total cholesterol } \\
\hline Intervention & $4.35^{\#, \$} \pm 1.13$ & $4.00^{\#} \pm 0.91$ & $4.08^{\$} \pm 1.06$ & $<0.00 I^{*}$ \\
\hline Control & $4.42 \pm 1.27$ & $4.26 \pm 1.18$ & $4.32 \pm 1.23$ & 0.319 \\
\hline Group difference & $P=0.635$ & $P=0.047^{*}$ & $P=0.088$ & \\
\hline \multicolumn{5}{|l|}{ Triglycerides } \\
\hline Intervention & $1.62^{\#} \pm 0.79$ & $1.49^{\#} \pm 0.72$ & $1.53 \pm 0.93$ & $0.028^{*}$ \\
\hline Control & $1.86 \pm 1.48$ & $1.68 \pm 0.87$ & $1.75 \pm 0.90$ & 0.260 \\
\hline Group difference & $P=0.097$ & $P=0.054$ & $P=0.053$ & \\
\hline \multicolumn{5}{|c|}{ Number of oral medications } \\
\hline Intervention & $0.97 \pm 0.55$ & $0.99 \pm 0.57$ & $0.98 \pm 0.57$ & 0.874 \\
\hline Control & $0.88 \pm 0.47$ & $0.84 \pm 0.46$ & $0.89 \pm 0.53$ & 0.438 \\
\hline Group difference & $P=0.140$ & $P=0.023^{*}$ & $P=0.212$ & \\
\hline \multicolumn{5}{|c|}{ Number of insulin types } \\
\hline Intervention & $\mathrm{I} .7 \mathrm{I} \pm 0.57$ & $1.64 \pm 0.63$ & $|.64 \pm 0.6|$ & 0.331 \\
\hline Control & I. $14 \pm 0.55$ & $\mathrm{I} .07 \pm 0.53$ & $\mathrm{I} . \mathrm{II} \pm 0.52$ & 0.063 \\
\hline Group difference & $P<0.00 I *$ & $P<0.00$ I* & $P<0.00$ I* & \\
\hline
\end{tabular}

Note: Symbols $(\#, \$, \wedge)$ indicate the statistical differences between the phases $(* P<0.05)$.

Abbreviations: BMI, body mass index; BP, blood pressure; HDL, high-density lipoprotein; LDL, low-density lipoprotein; SD, standard deviation. 
three phases of the study. Both LDL and total cholesterol significantly decreased in the intervention group during Ramadan and became significantly lower than the control group. However, such changes were partially lost after Ramadan. While both intervention and control groups continued to show improvement of high-density lipoprotein cholesterol during and after Ramadan, there was no statistically significant difference between the intervention and the control group. While body weight and BMI did not significantly change during the study, the slight baseline difference between groups (being lower in the control group) widen after Ramadan to become significant. On the other hand, the number of insulin types remained consistently higher in the intervention group compared with control group without any significant change during the study. Additionally, there were no changes in the blood pressure during the study.

Table 3 shows the impact of RFEP on glycemic control and hypoglycemia score. HbA1c levels were 9.79, 8.26, and 8.52 before, during, and after Ramadan in the intervention group, respectively $(P<0.001)$ and 10.04, 9.54, and 9.59 in the control group, respectively $(P<0.001)$. Both groups were significantly different at the end of the study $(P<0.001)$. Those who had targeted glycemic control $(<7)$ significantly increased during the study in the intervention ( $P=0.002)$ but not the control $(P=0.711)$, and the significant difference between both groups before Ramadan $(8.6 \%$ vs
$1.6 \%, P=0.013)$ significantly widen after Ramadan $(19.3 \% \mathrm{vs}$ $3.3 \%, P<0.001)$. The mean of hypoglycemia scores before, during, and after Ramadan was 14.21, 6.36, and 5.44 in the intervention group, respectively, $(P<0.001)$ and 14.01 , 13.46, and 9.27 in the control group, respectively $(P<0.001)$. Both groups were significantly different at the end of the study $(P<0.001)$.

As shown in Figure 1, the post-Ramadan reduction of both $\mathrm{HbA} 1 \mathrm{c}$ levels and hypoglycemia score was significantly higher in intervention compared with control groups $(-13.0 \%$ vs $-4.5 \%, P=0.004$ for $\mathrm{HbA} 1 \mathrm{c}$ levels and $-61.7 \% \mathrm{vs}-33.8 \%$, $P<0.001$ for hypoglycemia score). Similarly, post-Ramadan achievement of the target HbAlc $(<7)$ and hypoglycemia score $(<8)$ were more in intervention compared with control groups. In Table 4, multivariate linear regression analysis adjusted for age, sex, BMI, education, residence, and job showed $7.2 \%$ more post-Ramadan reduction in $\mathrm{HbAlc}$ $(P=0.004)$ and 3.16 points more post-Ramadan reduction in hypoglycemia score $(P<0.001)$ in the intervention group compared with the control group.

\section{Discussion}

General education programs that focus on self-management of diabetes care have been shown in several studies to have a beneficial effect on the glycemic control and other management outcomes in patients with T2D, both in the short- and probably the long-term as well. ${ }^{23,24}$ Moreover, education

Table 3 Impact of Ramadan focused education program on glycemic control and hypoglycemia score during the study phases in the intervention and control groups

\begin{tabular}{|c|c|c|c|c|}
\hline Variable & $\begin{array}{l}\text { Pre-Ramadan } \\
\text { Mean } \pm \text { SD } \\
\text { N (\%) }\end{array}$ & $\begin{array}{l}\text { During Ramadan } \\
\text { Mean } \pm \text { SD } \\
\mathbf{N}(\%)\end{array}$ & $\begin{array}{l}\text { Post-Ramadan } \\
\text { Mean } \pm \text { SD } \\
\text { N (\%) }\end{array}$ & $\frac{\text { Phase difference }}{P \text {-value }}$ \\
\hline \multicolumn{5}{|l|}{ HbAlc } \\
\hline Intervention & $9.79^{\# . \$ \pm 1.89}$ & $8.26^{\#} \pm 1.54$ & $8.52^{\$} \pm 1.61$ & $<0.00 I^{*}$ \\
\hline Control & $10.04^{\#, \$ \pm 1.47}$ & $9.54^{\#} \pm 1.38$ & $9.59 \$ \pm 1.79$ & $<0.00 I^{*}$ \\
\hline Group difference (repeated measure) & $P=0.233$ & $P \leq 0.00 I^{*}$ & $P \leq 0.00 I^{*}$ & \\
\hline \multicolumn{5}{|l|}{ HbAlc $<7$} \\
\hline Intervention & $12(8.6)$ & $34(24.3)$ & $27(19.3)$ & $0.002^{*}$ \\
\hline Control & $2(1.6)$ & $3(2.5)$ & $4(3.3)$ & 0.711 \\
\hline Group difference & $P=0.013^{*}$ & $P \leq 0.00 I^{*}$ & $P \leq 0.00 I^{*}$ & \\
\hline \multicolumn{5}{|l|}{ Hypoglycemia score } \\
\hline Intervention & $|4.2|^{\#, \$ \pm 8.50}$ & $6.36^{\#} \pm 6.17$ & $5.44^{\$} \pm 5.55$ & $<0.00 I^{*}$ \\
\hline Control & $\left.14.0\right|^{\#} \pm 5.10$ & $13.46^{\$} \pm 5.30$ & $9.27^{\#, \$} \pm 4.65$ & $<0.00 I^{*}$ \\
\hline Group difference & $P=0.815$ & $P \leq 0.00 I^{*}$ & $P \leq 0.00 I^{*}$ & \\
\hline \multicolumn{5}{|l|}{ Hypoglycemia score $<8$} \\
\hline Intervention & $35(25.0)$ & $95(67.9)$ & $103(73.6)$ & $<0.00 I^{*}$ \\
\hline Control & $10(8.2)$ & $15(12.3)$ & $4 I(33.6)$ & $<0.00 I^{*}$ \\
\hline Group difference & $P<0.00 I^{*}$ & $P<0.00 I^{*}$ & $P<0.00 I^{*}$ & \\
\hline
\end{tabular}

Note: Symbols $(\#, \$, \wedge)$ indicate the statistical differences between the phases $(* P<0.05)$.

Abbreviation: SD, standard deviation. 


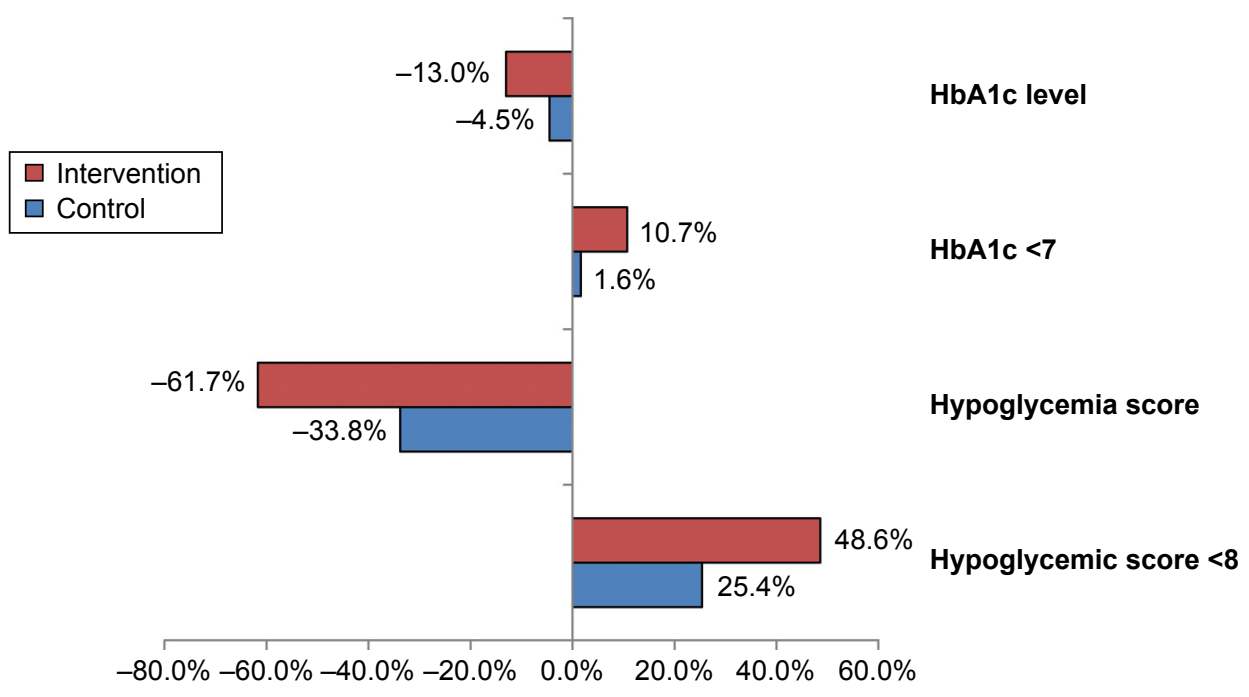

Figure I Post-Ramadan percent changes (compared with pre-Ramadan levels) of glycemic control and hypoglycemia score in the intervention and control groups.

of diabetes management is more critical for patients with T2D who insist to fast during Ramadan. However, some studies from other countries have shown that education could increase the awareness of adverse effects and proper management of diabetes. ${ }^{25,26}$ Fasting during Ramadan is a great challenge due to sudden alteration in daily dietary and physical activity, which may represent a considerable risk in some diabetic patients. ${ }^{3-5}$ For example, studies done in multiple countries showed that fasting may be responsible for up to sevenfold higher risk of hypoglycemia, especially among those on insulin and those who are physically active. ${ }^{11,16}$

The educational intervention received by the study patients was a multifaceted program run by different specialties, tailored for individual needs, and covering all standard recommendations for better diabetic management during Ramadan, including frequent glucose monitoring, medication and dose adjustments, proper meal planning, proper maintaining of physical activity, and situations that require breaking the fast. ${ }^{3,9}$

The current finding showed a beneficial impact of RFEP on the risk of hypoglycemia. Almost all the previous studies that examined the impact of similar education programs showed protective effect on the risk of hypoglycemia. ${ }^{15,16,27}$ For example, pre-Ramadan-focused education among UK Muslim patients with T2D was associated with approximately $60 \%$ reduction in hypoglycemia during Ramadan compared with fourfold increase in hypoglycemia among controls. ${ }^{16}$ Similarly, a prospective study in Pakistan showed that the majority of outpatients who attended two educational sessions on drug dosage and timing alteration, glucose monitoring, and dietary and lifestyle modifications did not have any serious acute diabetic complications during Ramadan. ${ }^{15}$ Additionally, hypoglycemia was less frequently seen during

Table 4 Multiple linear regression model to predict $\mathrm{HbAlc}$ and hypoglycemia score by the study groups ${ }^{\mathrm{a}}$

\begin{tabular}{|c|c|c|c|c|c|c|c|}
\hline \multirow[t]{2}{*}{ Variable } & \multicolumn{2}{|c|}{$\begin{array}{l}\text { Unstandardized } \\
\text { coefficients }\end{array}$} & \multirow[t]{2}{*}{$\begin{array}{l}\text { Standardized } \\
\text { coefficients }\end{array}$} & \multirow[t]{2}{*}{$t$-test } & \multirow[t]{2}{*}{$P$-value } & \multicolumn{2}{|c|}{$\begin{array}{l}95 \% \text { confidence } \\
\text { interval for B }\end{array}$} \\
\hline & B & Standard error & & & & Lower & Upper \\
\hline \multicolumn{8}{|l|}{ HbAlc (\%) } \\
\hline Constant & -17.75 & 3.86 & & -4.602 & $<0.001$ & -25.35 & -10.16 \\
\hline Intervention vs control group & -7.20 & 2.49 & -0.18 & -2.888 & 0.004 & -12.11 & -2.29 \\
\hline \multicolumn{8}{|l|}{ Hypoglycemia (points) } \\
\hline Constant & -12.15 & 1.74 & & 6.977 & $<0.001$ & 8.73 & -15.57 \\
\hline Intervention vs control group & -3.16 & 0.50 & -0.22 & 6.351 & $<0.001$ & 2.19 & -4.14 \\
\hline Age & 0.08 & 0.02 & 0.14 & -3.700 & $<0.001$ & 0.13 & 0.04 \\
\hline Education & 0.81 & 0.20 & 0.16 & -4.114 & $<0.001$ & 1.20 & 0.42 \\
\hline
\end{tabular}

Notes: $r$-square $=0.03$. ${ }^{a}$ Adjusted for age, sex, education, residence, job, BMI. Abbreviation: BMI, body mass index. 
Ramadan among fasting diabetic patients in UAE who received pre-Ramadan targeted education compared with their control counterparts $(27 \%$ vs $6 \%)$. The educationdirected modification in lifestyle and medication (type, dose, and timing) may have resulted in minimizing the risk of acute complications in our patients. ${ }^{25}$ Although to a much lesser extent, reducing the risk of hypoglycemia in the current study was also shown among the control group. This could be explained by the fact that there is generally good standard diabetes management in the clinic.

The current study showed a beneficial impact of RFEP on glycemic control and hypoglycemia. However, improvement in hypoglycemia was much more than the improvement in the glycemic control. This could be explained by the fact that considerable changes in $\mathrm{HbAlc}$ needs longer duration of sustained blood glucose control, which is beyond the 1-month Ramadan fasting. Pre-Ramadan education was associated with generally modest positive impact on glycemic control in the majority of previous studies ${ }^{15,16,27}$ but not all of them. ${ }^{28}$ Interestingly, unlike the risk of hypoglycemia, the impact of Ramadan fasting on biochemical parameters is probably mild. A couple of reviews showed that the majority of studies reported no change in $\mathrm{HbA} 1 \mathrm{c}$ in patients with T2D. ${ }^{29,30} \mathrm{On}$ the other hand, smaller number of studies showed decrease or increase of HbA1c during Ramadan fasting. ${ }^{29,30}$

The current study showed a mild positive impact of RFEP on lipid profile that was rapidly lost after Ramadan. Additionally, there was no beneficial impact on blood pressure or body weight. Similar to our results, pre-Ramadan targeted diabetes education in UAE was associated with insignificant changes in total cholesterol, triglycerides, and body weight. ${ }^{27}$ Additionally, pre-Ramadan-focused education among UK Muslim patients with T2D was associated with only $0.7 \mathrm{~kg}$ weight loss in the intervention and $0.6 \mathrm{~kg}$ weight gain in the control group after Ramadan. ${ }^{16}$ Unlike acute complications and glycemic control, body weight, blood pressure, and lipid profile were rarely used as an outcome for pre-Ramadan education programs in previous studies. On the other hand, several studies showed that Ramadan fasting has minimal impact on lipid profile of diabetic patients, with some studies showing decrease, increase, or no change of blood cholesterol. ${ }^{12,29,30}$ Additionally, it was shown that Ramadan fasting is associated with no weight change in $50 \%-60 \%$ but weight gain in $20 \%-25 \%$ of individuals. ${ }^{31}$

\section{Strengths and limitations}

The current study had strengths; it used a controlled design for measuring multiple outcomes including acute complications and biomedical parameters, measured during three phases (pre-, during, post-Ramadan). Nevertheless, we acknowledge some limitations. The nonrandomized approach is a limitation of this study, as the subjects were first enrolled into the intervention arm and then the control arm subjects were enrolled. However, this approach is not uncommon in the literature. ${ }^{32,33}$ According to Falk and Hagesund, this approach is considered appropriate if the purpose of study design was to mimic the clinical routine in the primary care setting, and to compare the intervention with the ordinary care without the opportunity to have this intervention. ${ }^{32}$

Moreover, regarding the comparability between the two arms in terms of the baseline characteristics, there were no statistically significant differences between the intervention and the control group for most demographic characteristics and clinical parameters. However, there were few differences, particularly in terms of residency and job status. There was a higher proportion of patients in the intervention group who were living outside Riyadh compared with the control group. Moreover, patients in the intervention group had more mixed types of insulin and hence had more tendency to hypoglycemia. However, the program was effective in reducing the risk of hypoglycemia despite the challenge that the intervention group might be more difficult to manage in this particular aspect. However, we believe the impact of these differences is minimal, as evidenced by maintaining the group difference in the outcome in multivariate analysis. Therefore, overall, we believe that study results are robust. However, these limitations should be taken into consideration when interpreting the results and conclusions of the study.

\section{Conclusion}

Ramadan educational program had a positive impact, with reduction of hypoglycemic risk, HbA1c, and LDL cholesterol. Therefore, it could be recommended for patients with increased risk of hypoglycemia during Ramadan fasting.

\section{Disclosure}

The authors report no conflicts of interest in this work.

\section{References}

1. Al-Baqarah S. (Chapter 2) verses. In: Abdullah Yusuf Ali. The Holy Quran. Ware: Wordsworth edition limited; 2000:183-185.

2. Hui E, Devendra D. Diabetes and fasting during Ramadan. Diabetes Metab Res Rev. 2010;26(8):606-610.

3. Suliman M, Abdu T, Elhadd T, Ibrahim S, Ahmed M, Malik R. Diabetes and fasting in Ramadan: can we provide evidence-based advice to patients? Sudan Med J. 2010;46(1):4-14.

4. Ahmadani MY, Riaz M, Fawwad A, Hydrie MZ, Hakeem R, Basit A. Glycaemic trend during Ramadan in fasting diabetic subjects: a study from Pakistan. Pak J Biol Sci. 2008;11(16):2044-2047. 
5. Aravind SR, Al Tayeb K, Ismail SB, et al; 2009 Ramadan Study Group. Hypoglycaemia in sulphonylurea-treated subjects with type 2 diabetes undergoing Ramadan fasting: a five-country observational study. Curr Med Res Opin. 2011;27(6):1237-1242.

6. Al-Nozha MM, Al-Maatouq MA, Al-Mazrou YY, et al. Diabetes mellitus in Saudi Arabia. Saudi Med J. 2004;25(11):1603-1610.

7. International Diabetes Federation. The global burden of diabetes. In: Diabetes Atlas. 5th ed. IDF; 2011.

8. Beshyah S. Fasting during the month of Ramadan for people with diabetes: Medicine and Fiqh united at last. Ibnosina J Med Biomed Sci. 2009;1(2):58-60.

9. Al-Arouj M, Assaad-Khalil S, Buse J, et al. Recommendations for management of diabetes during Ramadan: update 2010. Diabetes Care. 2010;33(8):1895-1902.

10. Jaleel MA, Raza SA, Fathima FN, Jaleel BN. Ramadan and diabetes: AsSaum (The fasting). Indian J Endocrinol Metab. 2011;15(4):268-273.

11. Salti I, Benard E, Detournay B, et al. A population-based study of diabetes and its characteristics during the fasting month of Ramadan in 13 countries: results of the epidemiology of diabetes and Ramadan 1422/2001 (EPIDIAR) study. Diabetes Care. 2004;27(10):2306-2311.

12. Yarahmadi S, Larijani B, Bastanhagh MH, et al. Metabolic and clinical effects of Ramadan fasting in patients with type II diabetes. $J$ Coll Physicians Surg Pak. 2003;13(6):329-332.

13. Pinelli NR, Jaber LA. Practices of Arab American patients with type 2 diabetes mellitus during Ramadan. J Pharm Pract. 2011;24(2):211-215.

14. Mohamed GA, Car N, Muacevic-Katanec D. Fasting of persons with diabetes mellitus during Ramadan. Diabetol Croatica. 2002;31:75-84.

15. Ahmedani MY, Haque MS, Basit A, Fawwad A, Alvi SF. Ramadan Prospective Diabetes Study: the role of drug dosage and timing alteration, active glucose monitoring and patient education. Diabet Med. 2012;29(6):709-715.

16. Bravis V, Hui E, Salih S, Mehar S, Hassanein M, Devendra D. Ramadan Education and Awareness in Diabetes (READ) programme for Muslims with type 2 diabetes who fast during Ramadan. Diabet Med. 2010;27(3):327-331.

17. International Diabetes Federation and the DAR International Alliance. Diabetes and Ramadan: Practical Guidelines. Brussels, Belgium: International Diabetes Federation; 2016. Available from: www.idf.org/ guidelines/diabetes-in-ramadan and www.daralliance.org. Accessed June 11, 2016.

18. Alomi YA. Update 2016 - Drug Therapy during Holy Month of Ramadan; 2016. Available from: https://www.researchgate.net/ publication/303836239_Update_2016-_Drug_Therapy_during_Holy_ Month_of_Ramadan. Accessed June 11, 2016.
19. American Diabetes Association. Standards of medical care in diabetes 2012. Diabetes Care. 2012;35(Suppl 1):S11-S63.

20. American Diabetes Association. Medical Management of Type 1 Diabetes. Alexandria, VA: American Diabetes Association; 2012.

21. American Diabetes Association. Medical Management of Type 2 Diabetes. Alexandria, VA: American Diabetes Association; 2012.

22. Hypoglycemic Health Association. Hypoglycemia Questionnaire; 2012. Available from: http://www.hypoglycemia.asn.au/wp-content/ uploads/HYPOGLYCEMIA_QUESTIONNAIRE.pdf. Accessed August 28, 2015.

23. Norris SL, Engelgau MM, Narayan KM. Effectiveness of selfmanagement training in type 2 diabetes: a systematic review of randomized controlled trials. Diabetes Care. 2001;24(3):561-587.

24. Thongsai S, Youjaiyen M. The long-term impact of education on diabetes for older people: a systematic review. Glob J Health Sci. 2013; 5(6):30-39.

25. Farid D, Rosenberg E, Bartlett G. Importance of education in managing type 2 diabetes during Ramadan. Can Fam Physician. 2014;60(6): $508-510$.

26. Fatim J, Karoli R, Chandra A, Naqvi N. Attitudinal determinants of fasting in type 2 diabetes mellitus patients during Ramadan. $J$ Assoc Physicians India. 2011;59:630-634.

27. Mustafa HE, Hashim T, Beshyah SA, et al. The effect of "targeted diabetes education" on glycemic control during Ramadan fasting. Ibnosina J Med BS. 2012;4(6):242-248.

28. Prataksitorn C, Singchungchai P. The effectiveness of Ramadan focused education on awareness and glycemic control of diabetic Muslims (type 2 diabetes) during Ramadan fasting. Int $J$ Public Health Res. 2014;4(1):405-411.

29. Benaji B, Mounib N, Roky R, et al. Diabetes and Ramadan: review of the literature. Diabetes Res Clin Pract. 2006;73(2):117-125.

30. Azizi F, Siahkolah B. Ramadan fasting and diabetes mellitus. Arch Iran Med. 2003;6(4):237-242.

31. Finch GM, Day JE, Razak, Welch DA, Rogers PJ. Appetite changes under free-living conditions during Ramadan fasting. Appetite. 1998; 31(2):159-170.

32. Falk M, Hagesund E. CBT-based group intervention for insomnia-a non-randomized trial in primary care. J Sleep Disord Ther. 2016;5(230): 2167-0277.1000230.

33. Jotzo M, Poets CF. Helping parents cope with the trauma of premature birth: an evaluation of a trauma-preventive psychological intervention. Pediatrics. 2005;115(4):915-919.
Patient Preference and Adherence

\section{Publish your work in this journal}

Patient Preference and Adherence is an international, peer-reviewed, open access journal that focuses on the growing importance of patient preference and adherence throughout the therapeutic continuum. Patient satisfaction, acceptability, quality of life, compliance, persistence and their role in developing new therapeutic modalities and compounds to optimize

\section{Dovepress}

clinical outcomes for existing disease states are major areas of interest for the journal. This journal has been accepted for indexing on PubMed Central. The manuscript management system is completely online and includes a very quick and fair peer-review system, which is all easy to use. Visit http://www. dovepress.com/testimonials.php to read real quotes from published authors. 